\title{
Designing with the Body - Somaesthetic Interaction Design
}

\author{
Kristina Höök \\ Royal Institute of Technology, \\ Sweden \\ khook@kth.se
}

\begin{abstract}
With the rise of ubiquitous technology, data-driven design and the Internet of Things, our interactions and our interfaces with technology will look radically different in the years ahead, incorporating changes like full body interaction, shape-changing interfaces, wearables and movement tracking apps. These changes offer an enormous opportunityindeed, a necessity-to reinvent the way we interact with the inanimate world. Once-familiar, everyday objects, from our phones to our vacuums, require novel interaction models not just typing text on screens, but, increasingly, movementbased, bodily communication. A qualitative shift is required in our design methods, from a predominantly symbolic, language-oriented design stance, to an experiential, felt, aesthetic stance permeating the whole design and use cycle.

I will discuss soma design - a process that allows designers to 'examine' and improve on connections between sensation, feeling, emotion, subjective understanding and values. Some design engages with bodily rhythms, touch, proprioception, bodily playfulness, but also with our values, meaningmaking processes, emotions, ethics and ways of engaging with the world. Soma design also provides methods for orchestration of the 'whole', emptying the digital and physical materials of all their potential, thereby providing fertile grounds for meaning-making and engagement.
\end{abstract}

Permission to make digital or hard copies of all or part of this work for personal or classroom use is granted without fee provided that copies are not made or distributed for profit or commercial advantage and that copies bear this notice and the full citation on the first page. Copyrights for components of this work owned by others than the author(s) must be honored. Abstracting with credit is permitted. To copy otherwise, or republish, to post on servers or to redistribute to lists, requires prior specific permission and/or a fee. Copyright 2018 SBC.

IHC 2018, Anais Estendidos do XVII Simpósio Brasileiro sobre Fatores Humanos em Sistemas Computacionais Outubro 22-26, 2018, Belém, Brasil

Palestra Convidada

\section{SHORT BIO}

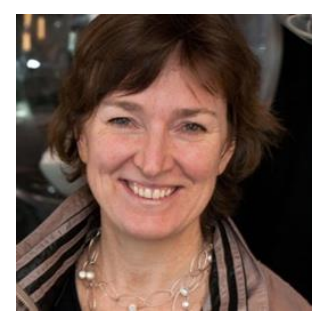

Kristina Höök is a full Professor in Interaction Design at Royal Institute of Technology (KTH), Stockholm Sweden. Höök is a frequent keynote speaker, known for her work on social navigation, seamfulness, mobile services, affective interaction and lately, designing for bodily engagement in interaction through somaesthetics.

Her competence lies mainly in interaction design and user studies helping to form design. Höök has obtained numerous national and international grants, awards, and fellowships including the Cor Baayen Fellowship by ERCIM (European Research Consortium for Informatics and Mathematics) for her thesis work in 1997, the INGVAR award from the Strategic Research Foundation (SSF) in 2004, she is an ACM Distinguished Scientist since 2014, and she is an ACM distinguished speaker. 